\title{
CrossFit Athletic Identity's Relationship to Sponsor Recall, Recognition, and Purchase Intent
}

\author{
Daniel J. Larson ${ }^{1 *}$, Jordan C. Wetherbee ${ }^{1}$, Paul Branscum² \\ ${ }^{1}$ Department of Health and Exercise Science, University of Oklahoma, 1401 Asp Ave. Norman, OK 73071 USA \\ ${ }^{2}$ Department of Kinesiology and Health; Miami University, 106 Phillips Hall, Oxford, OH 45056 USA
}

Corresponding Author: Daniel J. Larson, E-mail: larsondj@ou.edu

\section{ARTICLE INFO}

Article history

Received: May 10, 2019

Accepted: July 11, 2019

Published: July 31, 2019

Volume: 7 Issue: 3

Conflicts of interest: None

Funding: None

\begin{abstract}
Background: The CrossFit Open is a physical activity competition that allows athletes from across the world to compete in fitness challenges online, whereby participants document their progress via an event website. No apparent studies have examined participant event sponsorship in a case where sponsor messages are delivered primarily via an event website. Furthermore, current research has yet to consider the differential impact of audience athletic identity on sponsor messaging in such a context. Objective: The purpose of this study was to examine the relationship between CrossFit Athletic Identity (CAI) and the ability to recall and recognize official sponsors of a participant event conducted on an online platform. Methodology: A cross-sectional research design was used with a convenience sample $(n=170)$ of CrossFit Open participants from 36 affiliates in the South Central United States. A concurrent treatment validation with a subset of four participants utilized laboratory eye-tracking to evaluate the attention and viewing patterns within the CrossFit online platform. Results: CAI was not a significant predictor for sponsor recognition or recall $(\alpha=0.05)$. Only one of the case study participants had a recorded brand image fixation ( 0.29 seconds) during the eye-tracking assessments of their typical website interaction. Conclusion: While CAI was not associated with improved sponsor recognition and recall, the assessment of the participant website interactions suggest that participants in this study were not likely exposed to sufficient sponsor images. This highlights the need for critical evaluation of event website designs using eye-tracking or some other metric of visual exposure.
\end{abstract}

Key words: CrossFit, Athletic Identity, Sport Sponsorship, Eye-Tracking, Web Design

\section{INTRODUCTION}

The 'CrossFit Games' were launched in 2007 as a way to engage CrossFit users around the world, and determine the "fittest" man, woman, and team on Earth. The CrossFit Games occur over three stages: The Open, Regionals, and the world championship, also known as the Games. The CrossFit Open is a 5-week portion of the competition starting in late February whereby athletes complete a different workout each week. This allows athletes of all levels and ages to compete, and it has been suggested to be the "most inclusive sporting event in the world", as in 2016 there were 324,307 participants from 175 countries from North America, South America, Europe, Asia, Africa and Australia (CrossFit, 2016). With CrossFit's vast reach of members across the world and an Open event that has grown to over 300,000 participants (see Figure 1), CrossFit is capitalizing in on the associated sponsorship revenue. In September 2010, Reebok and CrossFit formed a 10-year, \$150 million partnership, which gave Reebok the title sponsorship of the CrossFit games, as well as the holder of exclusive rights to create CrossFit-branded footwear and apparel (Markelz, 2016; Imbo, 2015).
Companies participate in sponsorship activities to achieve strategic business objectives such as increasing awareness of their brand or product, connecting the brand with certain market segments, and increasing brand involvement in the community (Mullin, Hardy, \& Sutton, 2007). In North America, IEG has projected that $\$ 15.74$ billion will be spent in the sport sponsorship domain (a 5\% increase from 2015, \$14.99 billion), which accounts for $70 \%$ of the North American sponsorship market (IEG, 2016). As sponsorship is a large component of total revenue for sport events, it is crucial for managers to quantify, optimize, and market their sponsorship to increase organization performance (i.e. return on investment [ROI]). In addition to mass market exposure, a large measure of sponsorship effectiveness is whether brand messaging is reaching an intended target market. To that end, a recent review by Cornwell \& Kwon (2019) highlights sponsorship-linked marketing complexity that goes well beyond the "legacy media" approaches of the past. For example, market segmentation is now critical for business managers to understand and use, because it creates ever smaller, and therefore more effective, categories of consumers that are simi- 


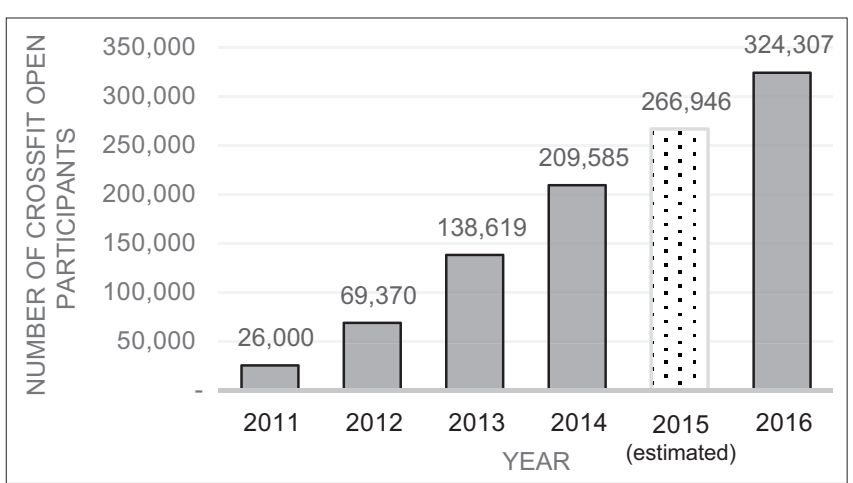

Figure 1. CrossFit open participation growth

lar in many domains; e.g., demographics, lifestyle activities, attitudes, and interests. (Murphy, 2010). Of specific interest in this study, there are different psychological factors that vary across sport event participants. Researchers have recently found evidence that a new segmentation based on an individual's perception of themselves in the athletic domain (i.e. athletic identity) is associated with measurable value (Lough, Pharr, \& Owen, 2014). This could lead to opportunities for companies to sponsor certain events due to the unique segmentation profile of the participants. Any differential value can also contribute to a company's ability to project and report ROI from its sponsorship endeavors.

While there is a significant amount of research covering general sponsorship effectiveness (typically defined as sponsor recall, recognition, and purchase intention), related to team identification and spectator events, there is little apparent research on athletic identification in participation sport event sponsorship (Lough et al., 2014), and none within online participant event sport sponsorship. A unique feature of the CrossFit Open is that participants complete this part of the competition in their local gym, while the event branding and messaging is primarily hosted online. After the athletes sign up, they submit their scores for the weekly workout to remain and potentially advance in the competition. Therefore, the CrossFit games' online platform offers a unique category of sponsorship messaging, an engaging online participant sporting event.

Past research on online sport sponsorship has had an emphasis on gambling websites rather than participation sport (e.g. Sportsbusiness International, 2006; Church-Sanders, 2011; Glendinning, 2009), and some limited work has also examined online sponsorship for professional teams' websites hosting sponsorships (e.g. Yu \& Stotlar, 2000). To date, sponsorship of online sport event participation has yet to be the subject of any published research.

Therefore, the purpose of this study was to examine the relationship between an individual's level of athletic identity and rates of sponsor recall, recognition, and purchase intention for official sponsors of a participant event hosted on an online platform. This motivates the central research question: Is there a relationship between an individual's level of CrossFit Athletic Identity (CAI) and recall, recognition, and purchase intent for official CrossFit Games sponsors? Based on the prior related studies, the following hypotheses were proposed:
$\mathrm{H} 1$ : There is a positive relationship between CAI and sponsor unaided recall.

H2: There is a positive relationship between CAI and sponsorship recognition (aided recall).

$\mathrm{H} 3$ : There is a positive relationship between CAI and sponsor purchase intention.

\section{METHODOLOGY}

\section{Participants and Design}

This study consisted of a post event online survey of CrossFit Open participants, and laboratory eye-tracking tests of a small subsample of event participants. The research design for this study was cross-sectional, descriptive, and correlational. This section will describe the sample and data collection procedures, the instrumentation employed, the case study methods, and the data analysis undertaken. All study protocols and procedures for human subject research were reviewed and approved by the authors' home institution Institutional Review Board.

The participants of this study were 2017 CrossFit Open participants $(\mathrm{N}=170)$. Data collection began in March 2017 and concluded by April 2017. There were two components of the study, a broad survey, and then four case studies to conduct a treatment validation. An a priori G-power analysis was conducted using an F-test and linear multiple regression with small effect sizes (based on Lough et. al, 2014), suggesting a minimum sample size of 160 participants for the survey (Tabachnick \& Fidell, 2013). The survey link was distributed to 36 different CrossFit affiliated gym owners in two states in the South Central US, where participants were recruited through non-probability convenience sampling using social media posts to gym websites (e.g. Facebook posts), and through word-of-mouth. Participants completed the survey on their own (using a phone, tablet or computer), but they were cautioned in their initial instructions to complete the survey in a distraction free setting, without accessing other sources on the internet (e.g. checking for correct sponsors). For the individual eye-tracking case studies $(n=4)$, participants were individually recruited using intercept sampling, and asked to visit an eye-tracking laboratory and were subsequently excluded from the follow-up online survey.

\section{Instrumentation}

The online survey portion of the study consisted of a 24-item questionnaire, with 9 sections. The first three sections confirmed the respondent's participation in the 2017 CrossFit Open, and measured their participation level (i.e. logging workouts online). Those who had not logged a workout into the website were excluded from data analysis. The participants reported their involvement with the online environment by the number of total visits and estimated number of minutes spent during each visit. They were also asked to report the physical space where they completed their workouts by selecting which affiliated gym they completed the majority of their workouts. 
The fourth section measured the participant's ability to use unaided recall to correctly identify the official sponsors of the 2017 CrossFit Open. Participants were asked to report, without cues or stimuli, any of the 14 official sponsors of the 2017 CrossFit Open. There was no penalty for incorrect answers or number of official sponsors not identified. This unaided recall measure has been reported to be valid in previous research of sport sponsorship (Biscaia et al, 2014; Ko, Kim, Claussen, \& Kim, 2008; Walsh, Ross \& Kim, 2008).

The fifth section was the modified Athletic Identity Measurement Scale (AIMS) for CrossFit athletes. The AIMS is a ten-item questionnaire created as a measurable domain-specific perceived importance judgment construct of one's personal worth and competence (Brewer, Van Raalte, \& Linder, 1993). The purpose of the scale is to measure an individual's athletic identity, which is "the degree of to which an individual identifies with the athlete role" (pg. 237). Brewer et al. (1993), conceptualized that an "individual with strong athletic identity ascribe great importance to involvement in sport/exercise and is especially attuned to self-perceptions in the athletic domain" (pg. 238). The original AIMS has been established as a reliable and valid measure of athletic identity (Brewer et al., 1993), and since then, studies have modified AIMS to sport specific identity roles (Horton \& Mack, 2000; Lough et al., 2014). Both of these studies used a modified version of AIMS for marathon runners and had similar internal consistency scores to Brewer's unmodified scale. The current study also used a modified version of the AIMS, i.e. CrossFit Athletic Identity (CAI) scale, to assess the specific role of a "CrossFit athlete" (see Table 1 for modified items). The internal consistency reliability and construct validity for the CAI scale were evaluated using Cronbach's alpha and factor analysis respectively. The sixth section asked participants to use aided recall to correctly recognize Cross-
Fit's sponsors. The aided recall (recognition) section had a list of 26 company names and logos (14 were official sponsors and 12 were non-sponsor distractors that were competitor or similar to the official sponsors). Participants received 1 point for each correct sponsor they identified as an official sponsor. The use of this aided recall measure has also been suggested to be valid in previous research of sport sponsorship (Biscaia et al., 2014; Ko et al., 2008; Walsh et al., 2008). The seventh section covered the respondent's purchase intention for official sponsor brands and asked two questions. The first was about the respondent's likelihood of purchasing products from official 2017 CrossFit Open sponsors and the second was the likelihood of the respondent to prefer official sponsors of the 2017 CrossFit Open over non-sponsors. Lough et al., used similar questions to measure purchase intention (2014). Both items were measured using a Likert scale from extremely unlikely (1) to extremely likely (7). The eighth section requested basic demographic information of the age and gender of the participants, with gender being identified by which gender division of the CrossFit Open they participated in. The final section asked about the participant's previous familiarity of the official CrossFit Open sponsors, asking participants to select which of the 14 official CrossFit sponsors they were familiar with before participating in the 2017 CrossFit Open.

\section{Case Study Methods}

The second component of this study was the analysis of several case studies using eye-tracking techniques. The use of eye tracking equipment to monitor how a spectator experiences a sporting event is on the forefront of studies examining the process of sponsorship recognition and recall. Eye-tracking is an important predictor in assessment

Table 1. CAI factor analysis results

\begin{tabular}{|c|c|c|c|}
\hline \multirow[t]{2}{*}{ Items } & \multicolumn{3}{|c|}{ Rotated factor matrix } \\
\hline & $\begin{array}{c}\text { Factor 1: } \\
\text { Social identity } \\
\text { associated with } \\
\text { CrossFit }\end{array}$ & $\begin{array}{l}\text { Factor 2: } \\
\text { Emotional } \\
\text { affinity for } \\
\text { CrossFit }\end{array}$ & $\begin{array}{c}\text { Factor 3: Singularity } \\
\text { of self-refection } \\
\text { associated with } \\
\text { CrossFit }\end{array}$ \\
\hline I consider myself a CrossFit athlete & 0.748 & & \\
\hline I have many goals related to CrossFit & 0.652 & & \\
\hline Most of my friends are CrossFit athletes & 0.613 & & \\
\hline CrossFit is the most important part of my life & & & 0.657 \\
\hline I spend more time thinking about CrossFit than anything else & & & 0.823 \\
\hline I need to participate in CrossFit to feel good about myself & & 0.620 & \\
\hline Other people mainly see me as a CrossFit athlete & 0.494 & & \\
\hline I feel bad about myself when I do poorly in CrossFit & & 0.807 & \\
\hline CrossFit is the only important thing in my life & & 0.470 & \\
\hline $\begin{array}{l}\text { I would be very depressed if I were injured and could not } \\
\text { compete in CrossFit }\end{array}$ & & 0.520 & \\
\hline Initial Eigenvalues & 3.759 & 1.554 & 1.119 \\
\hline Cronbach's $\alpha$ (items) & $0.75(4)$ & $0.7(4)$ & $0.76(2)$ \\
\hline Overall Cronbach's $\alpha$ (10 items $)=0.80$ & & & \\
\hline
\end{tabular}


of sponsorship because eye movements can serve as direct indicators of visual attention. Breuer and Rumpf (2012, 2015) have used eye tracking techniques to explore viewers' brand memory formation and the impact of measured attention to sport sponsor signage. They model the process by which attention to sponsorship information (signage) leads to recall of a sponsor brand. When predicting recall, they estimated that for every one second of increase in 'glance duration' the odds of sponsor recall increased by $308.0 \%$. These studies added three important considerations to the field of sponsorship research: 1) the role of the viewer's attention in sponsorship messaging, 2) the importance of visual appearance factors, and 3) the influence of overall exposure on memory formation. The primary relevance to the current study is to highlight the importance of evaluating the actual exposure and attentional behaviors of the participants.

Participants were recruited as a sub-sample of this population through local convenience intercept sampling. This part of the data collection occurred during the last two weeks of the 2017 CrossFit Open. Potential case study participants were eligible for inclusion if they were still participating in the 2017 CrossFit Open, and if they had logged most of their workouts online in the competition, as participants needed to be able to interact with the website without any assistance from the researchers. Participants then visited the Sports Business Analytics Laboratory to have an eye-tracking recording made of their interaction with the 2017 CrossFit Open website on a desktop computer. Once participants arrived in the laboratory, their eyes were calibrated for eye-tracking using the Gazepoint GP3 $(60 \mathrm{~Hz})$ equipment. The software uses infrared technology to track the participant's eyes with the GP3 eye-tracker that is located underneath the computer monitor. Using a 5-point calibration, the GP3 has a reported accuracy between 0.5 and 1 degree of the visual angle. Once calibrated, participants were asked to record their scores for the week and interact with the website as they normally had for the duration of the competition. Each viewing session was analyzed both qualitatively and using gaze duration and fixations on areas of interest (AOI), i.e. sponsor images, within their individual recordings.

\section{Data Management and Analysis}

For data preparation, incomplete surveys were pre-screened for the analysis of this study. Missing data were identified by running a frequency test on each question and a total of 4 respondents were removed from the analysis due to having a total of 4 or more questions without responses. After this process, there were 183 respondents in the sample. In instances where respondents had less than 4 missing values, a mean-replacement method was used. Responses greater than 2 standard deviations from the mean for continuous measures were classified as outliers. A total of 13 outliers were removed from the data for analysis, leaving a final remaining sample size of 170 . Descriptive statistics of the participants' demographic variables were calculated using SPSS 23.0. The researchers ran tests to make sure the assumptions of multiple regression and ANOVA were met, including, but not limited to: a Shapiro-Wilk test to determine if the measures were normally distributed $(\alpha=0.05)$, a test to determine if the residuals were homoscedastic, and multicollinearity diagnostics. Post-hoc analysis was performed on any group differences identified.

\section{RESULTS}

\section{Factor Analysis}

Maximum likelihood factor analysis was conducted to determine that the components of CAI (the 10 questions), loaded onto one global factor. An eigenvalue below 1 was used as an indicator that a factor may not be stable and should not be used. The 10 questions of the modified AIMS (CAI) were scrutinized using principal axis analysis with varimax rotation (see Table 1 ). The analysis produced three factors explaining a total of $64.3 \%$ of the variance for all the variables in the set. The first factor was labeled 'social identity associated with CrossFit', and included items 1-3 and 7 , explaining $37.6 \%$ of the variance. The second factor was labeled 'emotional affinity for CrossFit', it included items 6 , and 8-10 and accounted for $15.5 \%$ of the variance. The third factor was labeled 'singularity of self-reflection associated with CrossFit', and included items 4 and 5, explaining $11.2 \%$ of the variance. Overall, the factor analysis revealed that the analysis met the Kaiser-Meyer-Olkin Measure of Sampling Adequacy of a suggested minimum of $0.6(0.783)$.

Internal consistency reliability was tested by using Cronbach's Alpha. The CAI had a Cronbach's Alpha equal to 0.80 for the AIMS modified specifically for CrossFit athletes. Cronbach's Alpha was also conducted for the three subscales discovered by the factor analysis (see Table 1).

\section{Descriptive Data}

Descriptive statistics for all of the continuous variables are shown in Table 2. The respondents' mean age was 33 years $(\mathrm{SD}=7.7)$, with a median of 4 years participating in CrossFit workouts and a median of 3 years competing in the CrossFit Open. The respondents of this study were majority female $(62.94 \%)$. The average reported number of visits for the 5 weeks of the CrossFit Open was 25.9 (SD = 24.2) and the average reported number of minutes spent per visit was $21.7(\mathrm{SD}=35.0)$. The mean CAI score was $39.5(\mathrm{SD}=9.57)$. Respondents had a high recall rate for the title sponsor of the CrossFit Games (Reebok, 71.2\%), the next highest recall rate was at $44.7 \%$ for Rogue (see Table 3 ).

Even though the competition was hosted in an online environment, the weekly physical tasks that the participants had to enter online were competed in many different physical spaces (CrossFit affiliate or otherwise) which may have substantial differences between the physical spaces from promotional material present (posters, flyers, etc.) or brand of equipment used at the facility. To determine if the physical space had any statistical significant influence on the participants' recall, recognition, and purchase intent scores, mean differences for the dependent variables (raw recall and recognition scores and unfamiliar brand recall and recognition 
Table 2. Descriptive statistics $(n=170)$

\begin{tabular}{lcccc}
\hline Variable & Mean & SD & Min & Max \\
\hline Workout weeks logged & 4.82 & 0.56 & 1 & 5 \\
Number of website visits & 25.88 & 24.16 & 2 & 100 \\
Time spent per visit & 21.66 & 35.01 & 0 & 200 \\
$\begin{array}{l}\text { Years participating in the } \\
\text { CrossFit Open }\end{array}$ & 2.84 & 1.63 & 1 & 9 \\
Years participating in CrossFit & 4.19 & 2.45 & 0.5 & 13 \\
CAI Score & 39.45 & 9.57 & 19 & 66 \\
$\begin{array}{l}\text { Purchase intent for sponsor } \\
\text { Purchase preference for }\end{array}$ & 4.34 & 1.59 & 1 & 7 \\
$\begin{array}{l}\text { sponsor } \\
\text { Age }\end{array}$ & 4.22 & 1.52 & 1 & 7 \\
$\begin{array}{l}\text { Correct sponsor } \\
\text { recall (unaided) count }\end{array}$ & 32.92 & 7.65 & 17 & 58 \\
$\begin{array}{l}\text { Correct sponsor recognition } \\
\text { count }\end{array}$ & 5.19 & 2.58 & 1 & 12 \\
$\begin{array}{l}\text { Previously familiar sponsor } \\
\text { brands }\end{array}$ & 6.20 & 2.87 & 0 & 13 \\
$\begin{array}{l}\text { Unfamiliar sponsor recognition } \\
\text { count }\end{array}$ & 1.14 & 1.54 & 0 & 10 \\
\hline
\end{tabular}

Table 3. Official CrossFit games sponsors

\begin{tabular}{lccccc}
\hline \multirow{2}{*}{ Company } & \multicolumn{2}{c}{ Recall rates } & & \multicolumn{2}{c}{ Recognition rates } \\
\cline { 2 - 3 } \cline { 5 - 6 } & $\mathbf{N}$ & $\mathbf{\%}$ & & $\mathbf{N}$ & $\mathbf{\%}$ \\
\hline Reebok & 121 & 71.2 & & 152 & 89.4 \\
Rogue & 76 & 44.7 & & 136 & 80.0 \\
Assault Fitness & 47 & 27.6 & & 93 & 54.7 \\
Zevia & 24 & 14.1 & & 66 & 38.8 \\
Airrosti & 22 & 12.9 & & 75 & 44.1 \\
ROMWOD & 21 & 12.4 & & 86 & 50.6 \\
FitAid & 16 & 9.4 & & 67 & 39.4 \\
Gatorz & 9 & 5.3 & & 47 & 27.6 \\
Paleo Ethics & 6 & 3.5 & & 36 & 21.2 \\
Rock Tape & 5 & 2.9 & & 42 & 24.7 \\
5.11 & 3 & 1.8 & & 48 & 28.2 \\
Compex & 3 & 1.8 & & 21 & 12.4 \\
Eggology & 0 & 0 & & 4 & 2.4 \\
Trifecta & 0 & 0 & & 10 & 5.9 \\
\hline
\end{tabular}

scores) were tested across the physical spaces and there were no significant differences $(p>0.05)$.

\section{Multivariate Analyses}

\section{One-way ANOVA}

For coding the different groups of CAI scores, responses were coded in the following manner: CAI scores above the $67^{\text {th }}$ percentile (high CAI) were coded as 3 , for CAI scores between the $33^{\text {rd }}$ percentile and $67^{\text {th }}$ percentile were coded as 2 and CAI below the $33^{\text {rd }}$ percentile were coded as 1 . The percentile groups were constructed in the same manner as the Lough et al. study (2014). There were no statistically significant differences between the CAI groups for the count of correctly recalled sponsor scores determined by an ANOVA. Also, there were no statistically significant differences between the CAI groups and count of correctly recognized sponsor scores. Outputs for the ANOVAs are depicted below in Table 4.

There was however, a statistically significant difference between the CAI groups regarding the measure of intent to purchase products of the 2017 CrossFit Open sponsors as determined by a one-way ANOVA $(F(2,167)=3.378$, $p=0.036)$. A Tukey post hoc test discovered that the self-reported intent to purchase sponsor products was statistically significantly lower for a respondent with a "low" CAI score $(3.95 \pm 1.619, p=0.027)$ compared to a respondent with a "high" CAI score $(4.71 \pm 1.510)$, with a $\eta^{2}=0.038$ effect size. There were no statistically significant differences between the "high" CAI score and "mid" CAI score groups. There were also statistical differences between the groups regarding the consideration of the products of the official 2017 CrossFit Open sponsors over non-sponsors.

\section{Poisson regression}

A Poisson regression was used to model the count dependent variables given the multiple independent variables. Poisson regression was used because the outcome variables (recall, recognition, and new recognition) were count data and not overly-dispersed. The results are shown in Table 5. These dependent outcomes were separately modeled as associated with the following predictors: CAI score, age, gender, number of years participating in the CrossFit Open, number of years participating in CrossFit, number of visits to the CrossFit Games website, average time spent on each visit to the website, the total number of visits to the website, and a count of official sponsors previously familiar with before the CrossFit Open.

The first Poisson regression predicted the number of sponsor recall (unaided) counts. The value of the Pearson Chi-Square value/df was 0.631 , and the Omnibus Test revealed that the model was statistically significant with a p-value less than 0.001. The Test of Model Effects showed that the count of brands previously familiar with $(p<=0.001)$ was statistically significant.

For the number of sponsor recognition (aided) counts, the value of the Pearson Chi-Square value/df was 1.017 and the Omnibus Test revealed that the model was statistically significant $(p<0.001)$. The Test of Model Effects showed that age $(p=0.024)$ and count of brands previously familiar with $(p<=0.001)$ were statistically significant.

Finally the dependent variable of the count of sponsors that were recognized and previously unfamiliar to the participant we regressed on the same predictors (minus the familiar brands). This was done because the count of familiar brands was so dominant in the prior regressions. The Poisson regression for the new recognition count of brands previously unfamiliar to the respondent had Omnibus Test significance of $p=0.009$, indicating the model is statistically significant. The number of visits to the official CrossFit Games website 
Table 4. ANOVA groups

\begin{tabular}{|c|c|c|c|c|c|c|}
\hline \multirow{3}{*}{$\begin{array}{l}\text { Outcome variable } \\
\text { Purchase products of the } 2017 \text { CrossFit Open } \\
\text { partners and sponsors }\end{array}$} & \multirow[b]{2}{*}{ High CAI } & \multirow{2}{*}{$\begin{array}{l}\mathbf{N} \\
56\end{array}$} & \multirow{2}{*}{$\begin{array}{c}\text { Mean } \\
4.71\end{array}$} & \multirow{2}{*}{$\begin{array}{c}\text { SD } \\
1.51\end{array}$} & \multicolumn{2}{|c|}{$95 \% \mathrm{CI}$} \\
\hline & & & & & 4.31 & 5.12 \\
\hline & Mid CAI & 57 & 4.35 & 1.58 & 3.93 & 4.77 \\
\hline \multirow{6}{*}{$\begin{array}{l}\text { Consider the products of the } 2017 \text { CrossFit Open } \\
\text { partners and sponsors over non-sponsors/partners }\end{array}$} & Low CAI & 57 & 3.95 & 1.62 & 3.52 & 4.38 \\
\hline & Total & 170 & 4.34 & 1.59 & 4.09 & 4.58 \\
\hline & High CAI & 56 & 4.55 & 1.56 & 4.14 & 4.97 \\
\hline & Mid CAI & 57 & 4.16 & 1.51 & 3.76 & 4.56 \\
\hline & Low CAI & 57 & 3.95 & 1.44 & 3.56 & 4.33 \\
\hline & Total & 170 & 4.22 & 1.52 & 3.99 & 4.45 \\
\hline \multirow[t]{4}{*}{ Recall Score Count } & High CAI & 56 & 2.05 & 1.23 & 1.72 & 2.38 \\
\hline & Mid CAI & 57 & 2.25 & 1.26 & 1.91 & 2.58 \\
\hline & Low CAI & 57 & 1.93 & 1.40 & 1.56 & 2.3 \\
\hline & Total & 170 & 2.08 & 1.30 & 1.88 & 2.27 \\
\hline \multirow[t]{4}{*}{ Recognize Score Count } & High CAI & 56 & 5.79 & 2.61 & 5.09 & 6.49 \\
\hline & Mid CAI & 57 & 5.14 & 2.44 & 4.49 & 5.79 \\
\hline & Low CAI & 57 & 4.67 & 2.59 & 3.98 & 5.35 \\
\hline & Total & 170 & 5.19 & 2.58 & 4.80 & 5.58 \\
\hline
\end{tabular}

Table 5. Poisson regression results

\begin{tabular}{|c|c|c|c|}
\hline \multirow[t]{3}{*}{ Predictor } & \multicolumn{3}{|c|}{ Dependent variable } \\
\hline & Recall & Recognition & New Recognition \\
\hline & $\beta$ (SE) & $\beta$ (SE) & $\beta$ (SE) \\
\hline Intercept & $-0.077(0.3787)$ & $1.465 * * *(0.2435)$ & $1.516^{* * *}(0.51)$ \\
\hline Number of Open Years Participation & $0.086(0.058)$ & $0.034(0.0381)$ & $0.009(0.0792)$ \\
\hline Number of CrossFit Years Participation & $-0.012(0.0395)$ & $-0.012(0.0257)$ & $-0.028(0.0537)$ \\
\hline CAI Score & $-0.004(0.0062)$ & $0.001(0.0039)$ & $-0.008(0.0081)$ \\
\hline Gender & $0.034(0.1151)$ & $-0.098(0.0721)$ & $-0.34 * *(0.1488)$ \\
\hline Age & $0.006(0.0073)$ & $-0.011 * *(0.0049)$ & $-0.021 *(0.0107)$ \\
\hline Avg. Time Spent per Website Visit & $0.002(0.0015)$ & $0.001(0.0009)$ & $0.004 *(0.0019)$ \\
\hline Number of Visits to CrossFit website & $-0.002(0.0024)$ & $-0.001(0.0015)$ & $-0.008 * *(0.0039)$ \\
\hline Count of Familiar Brands & $0.083 * * *(0.0224)$ & $0.075 * * *(0.0142)$ & nw/a \\
\hline
\end{tabular}

${ }^{*} p<0.1 ; * * p<0.05 ; * * * p<0.01$

$(p=0.037)$ and gender $(p=0.022)$ were statistically significant in predicting the number of new brands recognized. There were a total of 194 counts of newly recognized brands that participants were previously unfamiliar with, and 95 participants recognized at least 1 new brand.

Researchers were unable to run a Poisson regression for the count of recalled new brands (previously unfamiliar to the respondent) due to the limited number of respondents having any new recalled brands. Only 29 (17.06\%) participants recalled 1 or more brands they were previously not familiar with, and of those, $23(79.31 \%)$ only recalled one new brand.

\section{Eye-tracking Analysis}

Six case study participants were initially recruited, but only four of them were able to have their eyes calibrated to be tracked for the study. The interaction time on the website ranged from just over a minute (1:08) to 6:44. The pages visited within the website included: home page, log-in page, score submission page, leaderboard page, and team page. None of the four case studies had any sponsor images present during their interaction time besides the CrossFit Games logo (Figure 2) that was present on every single page visited by the case studies, but nevertheless only one participant had one fixation on a brand that consisted of 0.289 seconds for the Reebok logo.

\section{DISCUSSION}

The purpose of this study was to evaluate event sponsorship messaging in an online platform (the CrossFit Open) and the influence of athletic identity on that process. Due to the popularity of CrossFit as a participant sport, combined with 


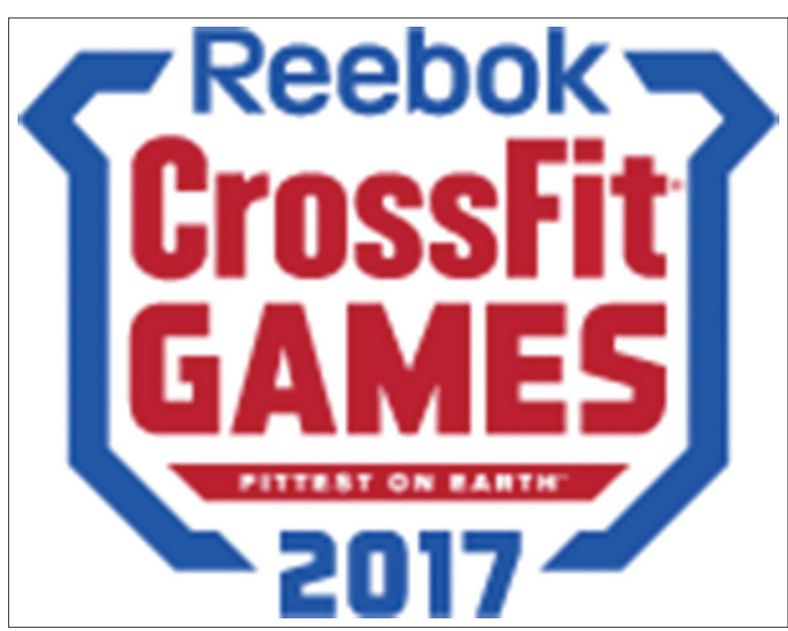

Figure 2. CrossFit Games Official Logo (CrossFit, 2017e, used with permission)

the sponsorship of sport being a multi-billion dollar industry, it is important for researchers to strive to understand how sponsorship messaging is processed by the audience. Sponsorship can be created at different levels, locations and mediums. As sponsorship is present at both in-person sport events and in the online environment which has the potential to reach the masses with its message, it is important to try to fill the gaps in the current research to include these new prominent channels. This study attempted to focus on, and study the relationship between the participant's athletic identify and the sponsorship message effectiveness in this online environment.

Most previous research with recall and recognition focused on participants watching a sport, but not competing or participating in a sport. While there is no apparent research on CrossFit sponsorship, some work has been done in other participant sports such as running. Lough et al. (2014), conducted a study of participants in the 2010 Las Vegas Rock 'n' Roll Marathon to examine if a participant's athletic identity (i.e. whether runner's identity) can be used to predict recognition, recall and purchase intentions of the event sponsors. The survey included a modified AIMS, the Runner Identity Scale (RID). Participants had an extremely high recall rate for the title sponsor $(96.97 \%)$, and total RID score was a significant independent variable in predicting the correct recall of the title sponsor. For the recognition portion the participants recognized the title sponsor (97.48\%), energy supplement sponsor $(76.63 \%)$, and bottled water sponsor $(80.62 \%)$, and once again total RID was a significant independent variable in the predicting ability to correctly recognize the official sponsors. For purchase intention, RID and gender were significant predictors for each of the purchase intention measures. The current study in some ways replicates Lough's study, but uses CrossFit and the alternative message delivery medium of an online environment. This study therefore uniquely adds to the growing area of sport participation and consumption research. The recognition rate of the title sponsor for this study was similar to the Lough et al. (2014) results. Rebook (CrossFit Open title sponsor) was correctly recognized by $89.4 \%$ of the participants, while
Lough et al. (2014) found $97.48 \%$ for their title sponsor. The secondary sponsor Rouge was also correctly recognized by $80.0 \%$ of the participants, again similar to the Lough et al. (2014) secondary sponsor recognition rate of $80.62 \%$.

The median age of the study's sample (33 years) falls within the reported range for the average 2016 CrossFit Open participant (CrossFit, 2016). The study did however have a greater percentage of female participants (62.94\%) compared to the 2016 CrossFit Open participants (42\%).

\section{Hypothesis Tests}

Statistical test results from the sample data were not in agreement with the research hypotheses 1 and 2 (insufficient evidence to reject the null), but were in agreement with research hypothesis 3 (null hypothesis rejected). Discussion of the specific statistical results follows.

H1. The CAI score was not a significant predictor of unaided recall count when controlling for age, gender, website exposure (visits and average visit time), prior CrossFit participation (in general and in the CrossFit Open), and prior brand familiarity. This is not consistent with previous findings by Lough, et al. (2014) who found that Athletic Identity influenced recall rates of sponsors by sport event participants. They found that RID was a significant variable $(p<0.001)$ in recalling the correct title sponsors, while age, gender, income, education, and relationship status were not significant $(p>0.05)$ (2014).

H2. The CAI score was not a significant predictor for aided recall count using the same control predictors. Again, this is not consistent with previous findings by Lough, et al. (2014) who found that Athletic Identity influenced recognition rates of sponsors by sport event participants. They found that RID was the only significant variable for predicting recognition of event sponsors $(p<0.01)$ and gender, age, income, education, and relationship status were not significant in predicting sponsorship recognition.

H3. As previously stated, there was a statistical difference in purchase intentions between individuals with "low" CAI and "high" CAI $(p=0.027)$ and no statistical difference between individuals with "mid" CAI versus "low" CAI and "high" CAI. This difference between "low" CAI and "high" CAI could potentially be used to create market segmentation within CrossFit Open participants.

\section{Control Variables}

The control variables included in the analyses had mixed influences on the recall and recognition of sponsors. These included age, gender, website exposure (visits and average visit time), prior CrossFit participation (in general and in the CrossFit Open), and prior brand familiarity.

In both estimated regression models for brand recognition, age displayed a negative relationship with recognition scores. Using the total recognition score, an additional year in age, was associated with respondent recognizing $0.011(95 \%$ CI, -0.021 to -0.001$)$ fewer sponsors $(p=0.024)$. In the case of new (previously unfamiliar) brand recognitions, although just short of statistical significance at the $\alpha=0.05$ level, 
every additional year of age of respondents was associated with a decreased recognition count of unfamiliar sponsors by $0.021(\mathrm{p}=0.056)$. These results could arise for two reasons, (1) older participants may be less involved in the event, therefore less likely to recognize sponsors, or (2) as participants get older, their memory of sponsors could simply be affected by natural aging declines. Future research should investigate not only this relationship but also whether or not it is actually linear in nature.

Prior brand familiarity was the strongest predictor of sponsor recall and recognition when included as a total score independent variable. For every additional previously familiar brand, respondents' count of recall sponsors would increase by $0.083(95 \%$ CI, 0.039 to 0.127$)$. For every additional previously familiar brand, respondents would have an increase count of 0.075 (95\% CI, 0.047 to 0.103$)$ recognized sponsors. This is expected, as sponsor brand familiarity would lead to an increase in recognition of event sponsors. This is consistent with prior studies which have either observed this relationship or statistically controlled for the effects (Breuer \& Rumpf, 2012, 2015).

When the dependent measure of brand recognition was instead coded to remove previously familiar brands a priori, some other control factors emerged as significant, and/or potentially important, predictors of new brand recognition. When considering only these new brand recognitions, the number of visits to the official website was a significant predictor in recognizing sponsors brands that the participants were not previously familiar with.

As discussed earlier in the literature review, Breuer and Rumpf (2012) emphasized the importance of controlling for the influence of exposure, viewer's attention and placement of signage to the research area. While the current study did not collect eye-tracking data for all participants, the exposure variables of website visit and time of visit were used as a proxy. Seemingly counterintuitive, every additional website visit was associated with a decrease in the count of newly recognized brands of 0.008 ( $95 \%$ CI, -0.016 to 0.000 ). Closer examination of the website design offers a possible explanation. Since the sponsor logos were not on every page of the website, it makes sense that the increased number of visits could be associated with fewer exposures to unfamiliar sponsor images. This could be directly related to the depth of interaction with the website, i.e. as visual attention and fixations would translate to better ability to recognize sponsors. If a participant's number of visits was high but time spent was low, they may simply have only had time to enter scores and check standings, and not necessarily explore the site and be exposed to the brand logos (see discussion of brand presentations below). Therefore, the number of visits could provide an invalid measure of high brand image interactions in this case, and not translate to increased recognition rates. Related to this concept of exposure though, and although not statistically significant, the estimated coefficient for average time on the site still suggested a potentially relevant positive relationship with recognition $(p=0.057)$, which is consistent with the overall brand exposure hypothesis. The latter finding is also consistent with previous sponsor recognition research which also measured effects of brand exposure (Becker-Olsen, 2003, Breuer \& Rumpf, 2012, 2015, Lardnoit \& Derbaix, 2001).

Gender was a significant predictor of new brand recognition, as males recognized about 0.34 (95\% CI, 0.022 to $0.149)$ more brands than females. This was contrary to the Lough et al. (2014) study because they found that gender was not a significant predictor in sponsorship recall and recognition rates.

\section{Individual Case Analysis}

While the case study component of the overall study rules out inferential analysis, it did offer important insights into why sponsorship effects on brand recall and recognition were muted in this case. With only one observed fixation on the CrossFit Games logo across all observed case study participants, and no presence of any sponsors aside from Reebok in the CrossFit Games logo, it appears that event participants were not getting enough exposure to the tertiary sponsors in the online environment to induce memory coding. Incidentally, the CrossFit Games website changed their layout from 2016, and there was significantly less visible signage for sponsors on the site. Specifically, on the previous year's website there was a side banner on each page that had the logos of all of the partners and sponsors of the CrossFit Games, depicted in Figure 3.

Another major change to the sponsor signage is that in 2016 the signage was static, while for 2017 the signage was on a rotating banner so that logos changed every few seconds to reveal other brands. The only static signage now is for Reebok, Rogue, and Airrosti (which were considered "proud partners" sponsorship).

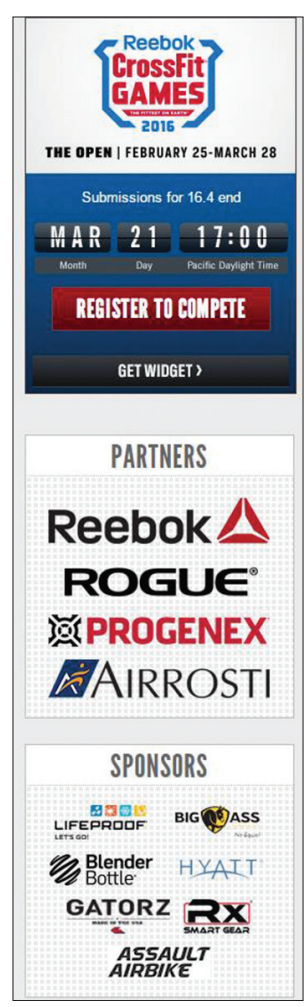

Figure 3. 2016 CrossFit Games Sponsor Logo Banner (CrossFit, 2017e, used with permission) 
For future events in the online environment, managers should consider the impact of signage placement and animation within the website (Breuer \& Rumpf, 2015). An examination of the most visited pages within a website, in addition to eye-tracking observations, could be good indicators for where to place sponsor images.

\section{Limitations}

The study had several limitations that need to be addressed. First, the study's sample was achieved through convenience sampling in just two South Central states, which means that the results of this study may not be generalizable to participants in other geographic areas and/or participants in the CrossFit Open who would not volunteer for such a study. Second, the focus of the study was specifically on CrossFit Athletic Identity, so the findings of this study may not be generalizable to other sports or participation events. Lastly, two of the sponsors of the CrossFit Games (Trifecta and ROMWOD) had sponsor logos added two weeks into the competition so they had less exposure to the event participants. Ideally, all of the sponsors would have the same time of exposure for the entire duration of the event. One external threat to the validity of the case studies is that participants might have interacted with the website differently in the lab setting than how they had interacted with the website previously during the 2017 CrossFit Open. For example, participants could be adjusted to using a different platform (tablet, laptop, or phone) to interact with the website. An internal threat to validity could arise from other confounding variables not tested in this study that would cause participants with high CAI scores to have higher or lower recall and recognition scores. Therefore, only statistically predictive relationships were analyzed, and no causation should be inferred.

\section{Recommendations for Future Research}

For sporting events that exist primarily in an online environment it could be beneficial for researchers to ask respondents if they recall seeing sponsors' logos or brands on the event website specifically, instead of asking them if they recall a brand being a sponsor of the event. Furthermore, more recently emphasized "top of mind" awareness should be considered as an additional outcome measure (Cornwell \& Kwon, 2019) A larger sample of the eye-tracking cases could also help event coordinators improve brand signage placement so that the most commonly visited pages have the presence of sponsors located on those pages.

\section{CONCLUSIONS}

In conclusion, sponsor recall and recognition rates of CrossFit Open participants cannot be attributed to the participant's CAI score either by simple tertile split for group mean comparisons, or by analyzing raw scores using multiple regression. Based on the qualitative assessment of website interaction, it is believed that the participants in this study context were not exposed to effective sponsor online signage which likely contributed to the low predictive rates of recognition and recall of sponsors based on CAI and other independent variables.

\section{REFERENCES}

Becker-Olsen, K. L. (2003). And now, a word from our sponsor. Journal of Advertising, 32(2), 17-32.

Biscaia, R., Correia, A., Ross, S., \& Rosado, A. (2014). Sponsorship effectiveness in professional sport: An examination of recall and recognition among football fans. International Journal of Sports Marketing \& Sponsorship, 7-23.

Breuer, C., \& Rumpf, C. (2012). The Viewer's Reception and Processing of Sponsorship Information in Sport Telecasts. Journal of Sport Management, 26, 521-531.

Breuer, C., \& Rumpf, C. (2015). The Impact of Color and Animation on Sport Viewers' Attention to Televised Sponsorship Signage. Journal of Sport Management, 29, 170-183.

Brewer, B. W., Van Raalte, J. L., \& Linder, D. E.(1993). Athletic identity: Hercules' muscles or Achilles heel? International Journal of Sport Psychology, 24(2), 237-254.

Church-Sanders, R. (2011). Game on. Sportbusiness International, (167), 44-48.

Cornwell, B. T., \& Kwon, Y. (2019). Sponsorship-linked marketing: Research surplus and shortages. Journal of the Academy of Marketing Sciences. DOI: https://doi. org/10.1007/s11747-019-00654-w

CrossFit. (2016, April 11). Statistics from the 2016 Open [video file]. Retrieved from https://games.crossfit.com/ video/statistics-2016-open

CrossFit. (2017a). Retrieved from https://map.crossfit.com.

Glendinning, M. (2009). Online gaming bets on sports. Sportbusiness International, (150), 64-67.

Horton, R. \& Mack, D.(2000). Athletic identity in marathon runners: Functional focus or dysfunctional commitment? Journal of Sport Behavior, 23, 101-119.

IEG. (2016). What sponsors want and where dollars will go in 2016. IEG Sponsorship Report. Retrieved from http:// www.sponsorship.com/IEG/files/71/711f2f01-b6fa46d3-96920cc1d563d9b7.pdf

Imbo, W. (2015, July 13). ESPN \& the CrossFit Games: How it all started \& what it means now. Retrieved from http:// boxlifemagazine.com/espn-the-crossfit-games-how-itall-started-what-it-means-now-the-2015-tv-schedule

Ko, Y. J., Kim, K., Claussen, C. L., \& Kim, T. H. (2008). The effects of sport involvement, sponsor awareness and corporate image on intention to purchase sponsors' products. International Journal of Sports Marketing \& Sponsorship, 9(2), 6-21.

Lardinoit, T., \& Derbaix, C. (2001). Sponsorship and Recall of Sponsors. Psychology \& Marketing, 18(2), 167-190.

Lough, N. L., Pharr, J. R., \& Owen, J. O. (2014). Runner Identity and Sponsorship: Evaluating the Rock 'n' Roll Marathon. Sport Marketing Quarterly, 23, 198-211.

Markelz, M. (2016). Has CrossFit Made Reebok Relevant Again? American Marketing Association. Retrieved from https://www.ama.org/publications/Mar- 
ketingNews/Pages/has-crossfit-made-reebok-relevantagain.aspx.

Mullin, B. J., Hardy, S., \& Sutton, W. A. (2007). Sport Marketing ( $3^{\text {rd }}$ ed.). Champaign, IL: Human Kinetics.

Murphy, D, (2010). The Value of Market Segmentation. Retrieved from http://www.salesvantage.com/article/1221/ The-Value-of-Market-Segmentation

Sportsbusiness International. Betting Firms Continue Sponsorship Spree. (2006). Sportbusiness International, (116), 17.
Tabachnick, B. G., \& Fidell, L. S. (2013). Using Multivariate Statistics $\left(6^{\text {th }}\right.$ ed.). Pearson.

Walsh, P., Ross, S., \& Kim, Y. (2008). Brand recall and recognition: A comparison of television and sport video games as presentation modes. Sports Marketing Quarterly, 17, 201-208.

Yu, C., \& Stotlar, D. (2000). Advertising banners on sport web sites. International Journal of Applied Sports Sciences, 12, 73-94. 